
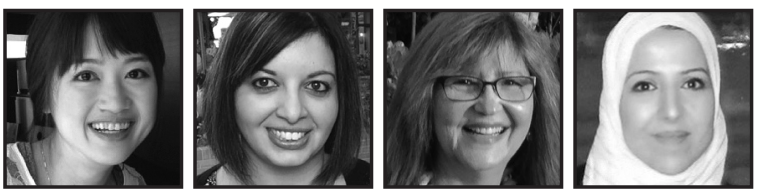

\title{
A Narrative Conception of Professional Development as a Nested Community
}

Hiroko Kubota, Jinny Menon, Dorit Redlich-Amirav, and Muna Saleh, University of Alberta

\section{ABSTRACT}

Thinking narratively (Clandinin, 2013), we inquire into our ongoing personal and professional development within the shaping of a nested community. By traveling to diverse worlds (Lugones, 1987), we attend to some of our stories to live by (Connelly \& Clandinin, 1999) and illuminate how living and telling stories within our community shapes and reshapes who we are and are becoming as narrative inquirers. Holding tensions and possibilities close, we create(d) a space where we can be ourselves and can personally and professionally learn alongside one another. It is both a safe space of coming home and starting new journeys.

\section{Storying and Restorying a Community Becoming as Shared From Our Four Perspectives}

For us (Hiroko, Jinny, Dorit, and Muna), the imagery of a door opening, sitting ajar, and standing closed has conveyed, at distinct times, the freedom, possibility, and difficulties which contour(ed) our personal and professional stories. This metaphor to live by (Lakoff \& Johnson, 1980/2003) has lived in many of our conversations, and we came to understand it as part of our embodied knowing (Johnson, 1989). We recognized, within this nested community, our relationships composed in the midst of challenges, triumphs, disappointments, and promise, continue to unfold even as our stories enfold us. 


\section{Jinny: Stepping Beyond the Threshold}

By attending to a range of human stories, they may be provoked to heal and to transform. Of course, there will be difficulties in affirming plurality and difference while also working to create communities. . . Many of us, however, for all the tensions and disagreements that surround us, reaffirm the value of principles like justice, equality, freedom, and commitment to human rights-indeed, without these, we cannot even argue for the decency of welcoming strangers to our midst. (Greene, 1992, p. 259)

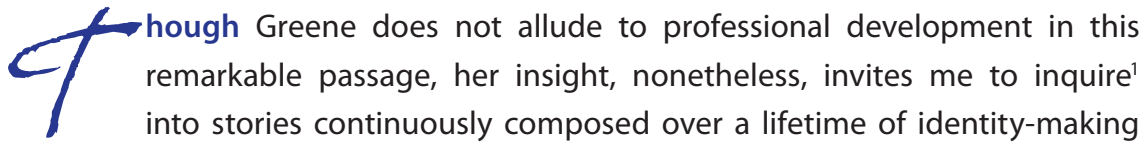
in relation with others. These are nuanced stories which "attend to the historical, the temporal, the contextual, and the relational" (Huber, Murphy, \& Clandinin, 2011, p. 347). Greene's words, in particular, "working to create communities," urge me to think more deeply about the ways in which my professional self intersects with my understanding of what it means to be in community. Professional development, for me then, in its best incarnation is personal, relational, and necessarily hard work. Fundamentally experiential, I perceive it as a living piece of architecture that is intricately wrought and built upon by immeasurable (mis)educative (Dewey, 1938/1997) curriculum-making experiences (Huber et al., 2011). Multilayered and fluid, it is continuously shaped by the stories we tell, live, retell, and relive (Clandinin, 2013; Huber, Caine, Huber, \& Steeves, 2013) as members of diverse communities. What follows then, are some understandings which inform(ed) me as a daughter, teacher, and doctoral student as I negotiate(d) my personal and professional identity in community, working within the overlapping commonplaces of learner, teacher, subject matter, and milieus (Schwab, 1973).

As a daughter. A daughter of South Asian parents, I found myself uneasily straddling worlds ${ }^{2}$ (Lugones, 1987) of home and school, experiencing subject matter in (in)harmonious ways. What was taught at home and within my community was not necessarily upheld at school. That is, a cultural narrative of old, which I read as prescribing definitive plotlines for males and females alike (see: Ghosh \& Guzder, 2011; Gill \& Mitra-Khan, 2009; Goel, 2005; Handa, 2003; Mitra, 2014). As Anzaldúa (1987/1999) conveys, a culture of tyranny exists whereby "culture informs our beliefs. We perceive the version of reality that it communicates" (p. 16). Likewise, Richardson (1997), drawing upon McClelland, cautions cultural stories "are not 'simply' stories but are narratives that have real consequences for the fates of individuals, communities, and nations" (p. 32). At home, it was my father's voice whose was loudest and my mother's voice 
whose was muted. Much like a bird without a song, I thought even as I felt that same silence attempting to swallow me whole.

As a teacher. Teaching proffered a different sense of community. I found community in the day-to-day interactions (Connelly \& Clandinin, 1988) between the students and myself, in the daily tending to of our unfolding relationships, what Clandinin et al. (2006) have expressed as a "curriculum of lives." Such a curriculum lived out in this classroom community meant that students, while encouraged to speak their minds, and to actively participate in various school-based activities, also entailed being responsible while showing care and respect for one another. There were challenges as well. Administering Provincial Achievement Tests (PATs) to students hampered by limited experience of the English language and additionally, unfamiliar with the North American milieu, weighed upon me. At the same time, professional development in the form of one- or two-day workshops, while helpful to some degree, did not sustain me as an educator. Moreover, though part of a school community, the lack of time to engage with colleagues in meaningful conversations about our work alongside students proved to be distressing.

As a doctoral student. Entering into a space created by the Centre for Research for Teacher Education and Development (CRTED), I was introduced to a research community that seeks to bridge difference not by flattening experience, but through courting resonances, ambiguity, and attending to multiplicities. Nested in this larger community an idea was born amongst four women of diverse heritage, working within different disciplines, and embodying (Johnson, 1989) a range of research interests, to gather as a response community of beginning narrative inquirers ${ }^{3}$ (Clandinin, 2013; Clandinin \& Connelly, 2000), in essence, to co-compose a counterstory (Lindemann Nelson, 1995) of professional development. This entailed a shift of the institutional narrative of what professional development ought to look like to one of sustaining possibility, whereby one had the authority to speak her mind without fear of reprisal from a space of safety. Within this relational space, I found solace in being able to speak, respond, and listen in mutually honourable ways. Here, not only the easy or so-called good stories could be shared, but also ones which, "if people move away and do not listen we may forever feel disconnected" (Paley, 1999, p. 59). These are stories which may strike emotional chords, bringing forth points of views that may not concur with one another. When this happens, rather than silencing conversation, Dorit, Hiroko, Muna, and I work within these complex feelings so to better learn from each other and to not privilege one person's knowing over another. The pressure to conform to monolithic ways of being, what could be an exclusionary exercise, does not exist in this space. Bateson's (1989) search for a term that could "assert collegiality and the fact 
the process is made possible by our differences" (p. 102), illuminates the significance in speaking from "a knowing rooted in experience" (hooks, 1994, p. 90). In this chosen community 4 (Lindemann Nelson, 1995), I have learned, "friends guide and learn from each other, especially in unexplored terrain" (Bateson, 1989, p. 103).

\section{Living in a Chosen Community Means Growing Professionally}

In accentuating Greene's (1992) passage earlier in this piece, I reflect on how identity-making within differing communities across time, has storied me personally and professionally. In doing so, I tried to give a sense of how markedly a chosen community on a particular university landscape has endowed me, a female of colour, with a safe space to speak, listen, and learn. As Clandinin and Rosiek (2007) thoughtfully articulate, "These lived and told stories and the talk about the stories are one of the ways that we fill our world with meaning and enlist one another's assistance in building lives and communities" (p. 35). As we four colleagues and friends build community, central to our narrative inquiries is a heartfelt commitment to human rights as lived out in our respective research puzzles (see: Kubota, 2014; Menon, 2015; Redlich-Amirav, 2015, Saleh, 2014). Equally crucial, this commitment is interwoven in our relations to one another, colleagues, participants, family, and friends. Grounded in a reciprocity of care, these are stories which we have come to recognize as nested within our chosen community and alongside one another, stories which transcend, (re)imagine (Sarbin, 2004), and (re)invent what it means to engage in professional development as equals, as humans whose voices do matter. It is Lorde (1984/2007) who intuitively imparts, "Community must not mean a shedding of our differences, nor the pathetic pretense that these differences do not exist" (p. 113). Daringly then, much like Huber et al. (2013), we continue to hope and dream, and we envision "possibilities for storying and restorying ourselves and one another into being; we wonder about new kinds of, or maybe forgotten or written over, obligations and ways of interacting and responding to and with one another" (p. 216).

\section{Hiroko: Knocking the Door and Entering Into a "Home"}

I was living in a silence when I first came to Canada. What should I do? Whom can I talk to? Where do I belong to? These were questions I recurrently asked myself at that moment. Prochnic (2011) states that silence is rooted in an expression of interrupted action. My voice was engulfed by silence, which took me out from "the space of appearance" (Arendt, 1958, p. 199). 
When I first arrived at the airport in January 2008, I realized that my suitcases were lost. This was my first day of coming to Edmonton to start a graduate program in the Faculty of Nursing at the University of Alberta. I was full of hope and ambition to start a new journey when saying goodbye to my family at the airport in Japan. This was my first time living abroad, so I put everything in my two big suitcases: clothes, books, photos, pens, snacks, soap, and so on. My two suitcases were packed with things familiar to me and were my home for me at that moment. I waited at the baggage lane with mixed emotions of excitement and anxiety. One by one, I became the only one waiting for luggage. When I found out that my suitcases were missing, I felt a hint of sadness starting to soak into my body. To shake this off, I ran out of the airport into the snowy bus stop to head towards a house where I rented a basement. I knocked at the door; I entered into a cold, empty basement with a small shoulder bag.

A few days later, I attended my first class. However, after the class, I decided to drop all my courses because I was unable to follow the discussions in English. I was overwhelmed by the complexities of the new language and the new terminologies I had never heard before. Above all, I was discouraged by my ability to listen to and speak English. In dismay, I wondered if I had to quit the program and go back to Japan. A hint of sadness finally penetrated into my body and was further developed into more realistic feelings of disappointment, fear, and uncertainty. I could not sleep that night, fighting with an invisible fear of isolation and disconnection from my home, my family, and anything familiar to me. This was my first experience of coming to Canada, characterized by the silence of interruption.

After several months of English study, I returned to my program. I was still struggling with both the language and feelings of anxiety and uncertainty. My identity was challenged as I felt awkward whenever I was unable to find a word in English. My stories of myself and the continuity of my life experiences seemed to have been interrupted since I had come to Canada. For me, my past and future did not appear to be linked at the horizon of the present moment (Kerby, 1991). Although the environments in Canada have become more familiar to me, I did not feel a sense of belonging here. I kept knocking on doors trying to find "home."

Since I started my doctoral program, I have attended a weekly meeting called "Research Issues," offered by the Centre for Research for Teacher Education and Development (CRTED). This is a response community where narrative inquirers learn about the methodology and learn to attend to stories in relational and responsive ways (Clandinin \& Caine, 2012). Several months later, I met Dorit; she is also a PhD student studying the same methodology of narrative inquiry. After we had a short conversation 
at Research Issues, we decided to talk more about narrative inquiry. This was our first meeting. We met once a week at a place called Hope House on campus, discussing the methodology, sharing our wonders and questions, and sending articles to each other to learn more about narrative inquiry. As we were both international students and taking the candidacy exam in several months, we could understand the feelings of frustration and vulnerability very well. I eventually felt more comfortable and safe to share stories with her.

Shortly after, Muna and Jinny joined us. We are a group of PhD students studying narrative inquiry and are in about the same stage of our programs despite being in different disciplines. The four of us started to meet weekly at Hope House. With a cup of coffee and snacks, we comfortably sat around a round table and shared our stories and writings. We came alongside each other and carefully listened to stories by travelling to each other's worlds with loving perception (Lugones, 1987). I travelled many places back and forth within their stories, which also encouraged me to retell and relive my own life stories (Clandinin, 2013).

Our space has quickly become a nested community where we all feel safe, loved, and nurtured. Within our nested community, my voice was finally released out of the silence and listened to by others. When I retold my lived and told stories, my interrupted past and present seemed to regain a momentum to be linked again. This temporal continuity allowed me to change and grow in educative ways (Dewey, 1938/1997). This nested community was created by a sense of care; its members always gave me encouragement and positive feedback, which helped me understand who I was, who I am, and who I am becoming (Clandinin \& Connelly, 2000). Thus, it is an important community where we all learn together and it is also a home where we feel a sense of belonging and acceptance. I knocked on the door at Hope House and finally entered "home," which was a significant transition for me both academically and personally.

As I moved from the silence of interruption into the warmth of our nested community, I came to truly appreciate the significance of being in a community and being able to express myself to others. Arendt (1958) emphasizes that human plurality is actualized by action and speech, which makes each human being unique and distinct. Disclosure of identity to others is significant in two ways: first it verifies the agency of human beings expressed through action and speech, and second, it demonstrates the "human togetherness" (p. 180) in which people are with others, not against them. Speech and action also meaningfully symbolize the concept of inception with which only human beings can introduce something new to the world, owing to their distinctiveness and human connectedness. Therefore, the fundamental element of the human condition is 
that human beings should be able to act and speak in the space of appearance, with a sense of agency and autonomy, which validates their very existence as a unique individual who can mark an initiation to the world.

\section{Dorit: Opening the Door Into a "Home"}

Every time we meet I have this feeling

Feeling of hope inside my body...

This is our third meeting at Hope House on campus at the University of Alberta.

I wonder about our meeting today, and butterflies are living in my belly as I am thinking about sharing my story. Is my story too hard to digest? Maybe today I will only listen to others. Maybe I will share only part of my story. These wonders are living within me. In a couple of minutes my friends will arrive.

As I open the front door at Hope House

I am still wondering about what to share.

As Hiroko, Muna, and Jinny arrive I feel happy and hopeful.

The butterflies leave and instead I feel something more solid in my belly, I feel longing and belonging, a feeling of home.

With smiles on their faces they arrive at the Hope library room and settle down around the round table. At the same time as they sit around the table I feel this thing called hope in my body. I feel this trust between us and a sense of home.

I love this gathering. I learn so much, and I know they will listen carefully to my story. I know they will initiate a dialogue and I will be inspired by their feedback.

Imagining these feelings of togetherness with Muna, Jinny, and Hiroko allow me to feel at home. "There is another sense in which learning can be coming home, for the process of learning turns a strange context into a familial one, and finally into a habituation of mind and heart" (Bateson, 1994, p. 213). For me, it became a relational learning space. It became a space of caring that enhanced my sense of trust, safety, and confidence. In this safe place, I started to recollect memories and further developed my research wonderings. This opportunity enabled me to look back into my vulnerable stories in an ongoing relational learning process. Dewey (1938/1997) defines a learning process through experience as the intersection of "continuity" and "interaction" between the personal, social, and material environment, and maintains that "every experience is a moving force" (p. 31). Dewey's attention to the intertwining of continuity, interaction, and situation is an unfolding process of experience. The relational experience that encompasses knowledge and context shapes identity -as Connelly and Clandinin (1999) further explain about the concept of "stories to 
live by"-where knowledge and context are connected to identity. As Clandinin and Huber (2002) eloquently wrote,

For us, identity is a storied life composition, a story to live by. Stories to live by are shaped in places and lived in places. They live in actions, in relationships with others, in language, including silences, in gaps and vacancies, in continuities and discontinuities. (pp. 161-162)

Muna, Jinny, Hiroko, and I came with our curiosity and hesitations. Our response community of narrative inquirers (Clandinin, 2013; Clandinin \& Connelly, 2000) became a nested community, a home for our "stories to live by."

I would like to share how our group has developed and where it all started. When I first came into the Centre for Research for Teacher Education and Development (CRTED) at the University of Alberta, I participated in weekly Research Issues, a gathering attended by graduate students, visiting and resident faculty, as well as other members of the community. I hesitated to talk and share as I came from a different country, from a different culture, and from a different discipline. As the only occupational therapist, I was shy, scared, and did not know what to share. With these feelings in my heart, I came every Tuesday afternoon to the Research Issues table - not because I thought it was expected of me-but because I wanted to learn what it is to be a narrative inquirer.

In this ongoing meeting of diverse lives and experiences, members inquire into their stories and shape possibilities of composing identities as researchers. For me, this gathering allows me to lovingly travel back to another time and place in my past. I traveled back to high school, to a time where I learned relationally. I remember when I started grade seven at the Agriculture Boarding School in Israel, knowing nobody there: I felt alone and did not know how to start building relationships. As I arrived in the middle of the year, I was shy and quiet. One of my classmates asked me if I would like to join her and some other friends when they study for the history exam. I immediately said "yes!" I was happy and excited as it represented a small hope for the beginning of a relationship. This invitation was an uplifting experience of belonging. At that time, I could not imagine how this relational way of learning was shaping and reshaping who I was and who I was becoming. For me, it was the start of a long-term relationship that allowed me to shape stories that I lived. This experience shaped my identity as a student in high school, and still shapes who I am and who I am becoming. These moments of belonging, and sense of hope and home, came to me again when we started to carefully compose our nested community. 
During my doctoral studies, I find myself again in this process of developing a nested community with Jinny, Muna, and Hiroko, my beloved community. I feel the same way I did in high school once again. I feel my thinking expanding as I live alongside my friends. Memories of my past coming into my mind fills me with excitement. As Dewey (1938/1997) helps me to learn, past experience shapes future experience. My three friends are part of my becoming as a narrative inquirer. They help me to feel my vulnerabilities, and at the same time they help me to trust with confidence, and open up a place and a space for more stories in the making. With their understanding and carefully listening, I was able to develop my narrative beginnings for my proposal as a doctoral student. We continue to build our nested community very carefully over time. This way of living alongside my friends became a part of who I am and part of my identity.

It is a couple of months that we are meeting together, once a week at Hope House. Hope House is part of the university. It is an old wood building with a Hope library. At the library, there is a round table with chairs, and many books, journals, and dissertations about hope. In this place with a hopeful atmosphere, it is like being at home. This feeling of home reminds me of what Caine (2010) thoughtfully articulates about narrative beginnings, about home as place(s) and the interconnections within her memory. The way she carried her memory of home provided her with a sense of belonging. For me, our place at Hope House became a space of hope.

Farran, Herth, and Popovich (1995) describe a relational hope process as the heart of hope, which enables people to give hope to each other by the ability to lovingly travel to each other's worlds (Lugones, 1987). For my understanding, the process of who we are and who we are becoming is a process of hope. It is a process of hope because "hope breathes life into the human spirit. With hope, human beings strive for and strengthen their capacities for growth and change" (Koenig \& Spano, 2007, p. 46). Many times, Jinny, Muna, and Hiroko function as sources of hope for me. During this process of my doctoral work, which encompasses tensions, ambiguity, and loneliness in general, studying in a different language makes this process even more complicated. Coming from a different culture, and a different language, also fills me with tensions, fears, and uncertainties. When these feelings of fear arrive and thoughts about the amount of strength needed to overcome this process intrude, sharing difficulties and being willing to listen become paramount. Dufault and Martocchio (1985) relate hope to an external process where other people are able to promote, engender, and sustain hope when the individual's own hope resources seem to be depleted. Indeed, our connectedness within our nested community expresses mutual dependence, intimacy, shared hopes, and a sense of belonging. Like Bateson (1994), I feel that "discovering the connections 
and regularities within knowledge you already have is another kind of homecoming, a recognition that feels like a glorious game or a profound validation" (pp. 205-206). It is very meaningful for me to learn, and grow, through intimate connections with close friends, our nested community. This community is a homecoming, a feeling of togetherness and care where we don't really know what life will bring us, and we would like to be open to surprise (Lugones, 1987). As we are traveling to each other's world, we have the full meaning of who we are and who we are becoming.

\section{Muna: Awakening to Doors of Possibility...}

"Community means you can be yourself" (Paley, 1995, p. 97)

Smiling as soon as I see them, I embrace my friends and works-in-progress group members with a combination of joy and relief. We have agreed to meet this week at Hope House and I am feeling very much in need of hope as I move forward in my doctoral program. My candidacy exam will be taking place in a few weeks and I am feeling the sharp edges of anxiety as time encroaches upon the space between me and my upcoming exam date. I wonder if this anxiety shows as I sit at my usual spot at the small wooden table. I think that it must because my friends seem to look intently at me as they ask how I am doing. Taking a deep breath, I start to share...

This story fragment of a moment lived alongside my works-in-progress group friends invites me to contemplate the many profound and embodied shifts I have experienced in composing my life as a woman, mother, curriculum-maker (Huber et al., 2011), graduate student, and narrative inquirer (Clandinin, 2013; Clandinin \& Connelly, 2000) over the past year. Almost a year ago, Hiroko, Dorit, Jinny, and I felt that it would be a good idea to try meeting once a week as we were all in the midst of engaging in writing proposals, approaching candidacy exams, and/or commencing doctoral research projects. We were already acquainted through our work alongside one another in doctoral courses and in the weekly Research Issues group meetings at the University of Alberta's ( $U$ of A) Centre for Research for Teacher Education and Development (CRTED) when we discussed the possibility of extending this relational knowing through a weekly works-in-progress group. I am thankful that we acted upon this possibility-our group has become one of my most cherished sustaining stories (Lopez, 1990; Paley, 1997) as I continue to compose my life alongside colleagues, family, friends, and research participants.

While we most often engage in works-in-progress meetings at Hope House, the physical location of our discussions has shifted to many other places. We have Skyped 
with members who were conducting their research abroad, and we have also met in coffee shops and at the CRTED. While the physical locale of our discussions undoubtedly shapes what we choose to share at any given moment, Heidegger's concept of dwelling reminds me that spaces are permeated with meaning largely because of the relationships nurtured within them: "Dwelling is said to consist in the multiple 'lived relationships' that people maintain with places, for it is solely by virtue of these relationships that space acquires meaning" (as cited in Basso, 1996, p. 106). Our chosen community (Lindemann Nelson, 1995) nested within a multiplicity of communities, is so much more than where we happen to be meeting. Infinitely more profound is who we are and who we are becoming as people and professionals alongside one another in these spaces.

Bateson (1989) reminds me that "specific everyday tasks can be life-giving, binding individuals to each other and to the past. They can also be opened up as areas of choice, becoming the building blocks of identity" (p. 131). While I am drawn to many parts of Bateson's assertion, my attention (re)turns again and again to the idea that certain activities "bind individuals to each other and to the past" and how these activities contribute to identity-making. These words resonate strongly for me because, like Caine (2010), I "realize that in the midst of seeking a new story to live by, each story will always begin with my past" (p. 1304). Every time Hiroko, Dorit, Jinny, and I choose to meet, we embody our diverse lived narratives, including personal, cultural, social, institutional, relational, linguistic, religious, and familial stories (Clandinin, 2013) planted within us at some point in the continuum of our life compositions. I am very mindful of this as a Canadian-born Muslim woman, educator, and student of Palestinian heritage. However, while my friends and I are different in terms of our personal (her)stories, we are building our (chosen) community and our identities alongside one another in multilayered and profound ways with our relational tellings and re-tellings (Clandinin \& Connelly, 2000). As Greene (1992) so poignantly elucidated:

To open up our experience (and, yes, our curricula) to existential possibilities of multiple kinds is to extend and deepen what we think of when we speak of a community. If we break through and even disrupt a surface equilibrium and uniformity, this does not mean that particular ethnic or racial traditions ought to replace our own. (p. 254)

Our works-in-progress group has allowed me to travel to the myriad worlds (Lugones, 1987) we each inhabit and traverse, allowing me to see and feel from vantage points that would not have been possible otherwise, whilst simultaneously honouring my embodied experiential knowing. 
Reflecting upon our conversations over the last year, and the story fragment I shared at the beginning of this piece, I resonate strongly with Morris' (2002) emphasis on the profoundly moral undercurrent of stories. Drawing upon Coles (1989), Morris (2002) asserted that sharing personal and professional experiences "incur an obligation on the listener. Such stories exert a kind of 'call'" (p. 197). My friends have encouraged me to inquire into my lived and told stories in ways that have made visible spaces to emerge for re-telling and re-living these stories as a woman, curriculum-maker, and student alongside others. As a narrative inquirer in the making, this chosen community helps me to relationally live what Downey and Clandinin (2010) emphasized when they noted, "Narrative inquiry understands any situation as nested within an almost endless array of other situations and, rather than sort them out, seeks to understand and explore the layers of complexity involved in living a life" (p. 388).

Our discussions are not without tensions. There are times when I feel uncomfortable with, or uncertain about, what I am sharing or attending to for a multitude of reasons. However, as Clandinin, Lessard, and Caine (2012) remind me,

Conversational spaces are not spaces to exchange and confirm already familiar understandings, but, rather, are characterized by emergent occasions for exploring other possible stories. They are relational spaces characterized by mutuality and possibility, where embodied, lived tensions become resources or triggers for telling and retelling stories. (p. 18)

Indeed, within the tensions I experience at times, liminal spaces (Heilbrun, 1999), spaces rife with both unsteadiness and possibility whereby stories can be retold and relived with imagination and improvisation (Bateson, 1989), often become visible. Looking forward, and thinking of the many shifts that have occurred and will continue to occur as we engage in this work together, I am reminded of Kerby's (1991) statement that "the unfolding of time is the unfolding of our history" (p. 19) ... and I wonder what our co-composed (her)story will bring over time ...

\section{Conclusion}

As we turn our gazes forward, we imagine possibilities in sharing our multiple perspectives through our unique voices (Ely, 2007). We continue to metaphorically play with opened, ajar, and closed doorways as liminal spaces (Heilbrun, 1999) in personal and professional development. Together, in the midst of these storied archways, we embrace the multiplicity of our lived stories as beginning narrative inquirers. 


\section{Notes}

1. Guided by the three-dimensional narrative inquiry space of temporality, sociality, and place (Clandinin \& Connelly, 2000), we engage in autobiographical narrative inquiry (Clandinin, 2013; Saleh, Menon, \& Clandinin, 2014) into our lived stories alongside one another. As both phenomena and methodology (Clandinin \& Connelly, 2000), narrative inquiry is theoretically grounded in Dewey's (1938/1997) philosophy of experience as education and Schwab's (1973) concept of the practical in education.

2. A 'world,' Lugones (1987) elucidated, "need not be a construction of a whole society. It may be a construction of a tiny portion of a particular society. .. Some 'worlds' are bigger than others" (p. 10).

3. While we engage in autobiographical narrative inquiry for this paper, we are each in the midst of coming alongside diverse research participants for our respective narrative inquiries.

4. A community of choice, Lindemann Nelson (1995) explicates, can provide a space by which its members "can tell self-defining stories" (p. 28).

5. In my doctoral research, I inquire into the experiences of people who are homeless in Japan, with a focus on how a sense of home was/is constructed-in mind and physically-before and after becoming homeless, and how they experienced the transitions of 'home' (Kubota, 2014).

\section{References}

Anzaldúa, G. (1987/1999). Borderlands/La frontera: The new mestiza. San Francisco: Aunt Lute Books.

Arendt, H. (1958). The human condition. Chicago: The University of Chicago Press.

Basso, K. H. (1996). Wisdom sits in places: Landscape and language among the Western Apache. Albuquerque, New Mexico: University of New Mexico Press.

Bateson, M. C. (1989). Composing a life. New York: A Plume Book.

Bateson, M. C. (1994). Peripheral visions: Learning along the way. New York: Harper Collins.

Caine, V. (2010). Narrative beginnings: Traveling to and within unfamiliar landscapes. Qualitative Health Research, 20(9), 1304-1311. doi:10.1177/1049732310367500

Clandinin, D. J. (2013). Engaging in narrative inquiry. Walnut Creek, CA: Left Coast Leaf Press.
Clandinin, D. J., \& Caine, V. (2012). Narrative inquiry. In A. A. Trainor \& E. Graue (Eds.), Reviewing qualitative research in the social sciences (pp. 166-179). New York: Routledge.

Clandinin, D. J., \& Connelly, F. M. (2000). Narrative inquiry: Experience and story in qualitative research. San Francisco: Jossey-Bass Publishers.

Clandinin, D. J., \& Huber, J. (2002). Narrative inquiry: Toward understanding life's artistry. Curriculum Inquiry, 32(2), 161-169. doi:10.1111/1467-873X.00220

Clandinin, D. J., Huber, J., Huber, M., Murphy, M. S., Murray Orr, A., Pearce, M., et al. (2006). Composing diverse identities: Narrative inquiries into the interwoven lives of children and teachers. New York: Routledge.

Clandinin, D. J., Lessard, S., \& Caine, V. (2012). Reverberations of narrative inquiry: How resonant echoes of an inquiry with early school leavers shaped further inquiries. Educacao, 
Sociedade \& Culturas, 36, 7-24. Retrieved from http://www.fpce.up.pt/ciie/revistaesc/ ESC36/ESC36_D.Jean_Sean\&Vera.pdf

Clandinin, D. J., \& Rosiek, J. (2007). Mapping a landscape of narrative inquiry: Borderland spaces and tensions. In D. J. Clandinin (Ed.), Handbook of narrative inquiry: Mapping a methodology (pp. 35-75). Thousand Oaks, CA: Sage.

Coles, R. (1989). The call of stories: Teaching and the moral imagination. Boston: Houghton Mifflin.

Connelly, M., \& Clandinin, D. J. (1988). Teachers as curriculum planners: Narratives of experience. New York: Teachers College Press.

Connelly, F. M., \& Clandinin, D. J. (1999). Shaping a professional identity: Stories of educational practice. New York: Teachers College Press.

Dewey, J. (1938/1997). Experience and education. New York: Simon \& Schuster.

Downey, C. A., \& Clandinin, D. J. (2010). Narrative inquiry as reflective practice: Tensions and possibilities. In N. Lyons (Ed.), Handbook of reflection and reflective inquiry: Mapping a way of knowing for professional reflective practice (pp. 285-397). Dordrecht, Netherlands: Springer.

Dufault, K., \& Martocchio, B.C. (1985). Symposium on compassionate care and the dying experience. Hope: Its spheres and dimensions. Nursing Clinics of North America, 20(2),

Ely, M. (2007). In-forming re-presentations. In D. J. Clandinin (Ed.), Handbook of narrative inquiry: Mapping a methodology (pp. 35-75). Thousand Oaks, CA: Sage.

Farran, C. J., Herth, K. A., \& Popovich, J. M. (1995). Hope and hopelessness: Critical clinical constructs. Thousand Oaks, CA: Sage.

Ghosh, R., \& Guzder, J. (2011). Re-bordering immigrant and refugee identities in Quebec's multicultural society: The case of South Asian (SA) youth. Canadian and International Education / Education canadienne ET international, 40(2), 12-33. Retrieved from http:// ir.lib.uwo.ca/cie-eci/vol40/iss2/3

Gill, A., \& Mitra-Khan, T. (2009). Explaining daughter devaluation and the issue of missing women in South Asia and the UK. Current Sociology, 57(5), 684-703. doi:10.1177/0011392109337652
Goel, R. (2005). Sita's trousseau: Restorative justice, domestic violence, and South Asian culture. Violence Against Women, 11(5), 639-665. doi:10.1177/1077801205274522

Greene, M. (1992). Multiculturalism and the expanding community. Journal of Negro Education, 61(3), 250-261. doi: $10.2307 / 2295246$

Handa, A. (2003). Of silk saris and mini-skirts: South Asian girls walk the tightrope of culture. Toronto, ON: Women's Press.

Heilbrun, C. (1999). Women's lives: The view from the threshold. Toronto, ON: University of Toronto Press.

hooks, b. (1994). Teaching to transgress: Education as the practice of freedom. New York: Routledge.

Huber, J., Caine, V., Huber, M., \& Steeves, P. (2013). Narrative inquiry as pedagogy in education: The extraordinary potential of living, telling, retelling, and reliving stories of experience. Review of Research in Education, 37(12), 212-242. doi:10.3102/0091732X12458885

Huber, J., Murphy, M. S., \& Clandinin, D. J. (2011). Places of curriculum making: Narrative inquiries into children's lives in motion. London: Emerald.

Johnson, M. (1989). Embodied knowledge. Curriculum Inquiry, 19(4), 361-377. Retrieved from http://www.jstor.org/stable/1179358

Kerby, A. P. (1991). Time and memory. In Narrative and the self: Studies in continental thought (pp. 15-31). Bloomington, IN: Indiana University Press

Koenig, T., \& Spano, R. (2007). The cultivation of social workers' hope in personal life and professional practice. Journal of Religion and Spirituality in Social Work, 26(3), 45-61. doi:10.1300/J377v26n03_03

Kubota, H. (2014). A narrative inquiry into the experiences of people in Japan who are homeless or precariously housed. Unpublished doctoral proposal. Edmonton, AB: University of Alberta.

Lakoff, G., \& Johnson, M. (1980/2003). Metaphors we live by. Chicago: The University of Chicago Press. 
Lindemann Nelson, H. (1995). Resistance and insubordination. Hypatia, 10(2), 23-40. doi:10.1111/j.1527-2001.1995.tb01367.x

Lopez, B. (1990). Crow and weasel. San Francisco: North Point Press.

Lorde, A. (1984/2007). Sister outsider. Freedom, CA: The Crossing Press.

Lugones, M. (1987). Playfulness, "world"-traveling, and loving perception. Hypatia, 2(2), 3-19. doi:10.1111/j.1527-2001.1987.tb01062.x

Menon, J. (2015). A narrative inquiry into the experiences of South Asian girls, mothers, and teachers in curriculum making in and out of schools. Unpublished doctoral proposal. Edmonton, AB: University of Alberta.

Mitra, A. (2014). Son preference in India: Implications for gender development. Journal of Economic Issues, 48(4), 1021-1037. Retrieved from http://socialeconomics.org/ Papers/Mitra4A.pdf

Morris, D. (2002). Narrative, ethics and pain: Thinking with stories. In R. Charon \& $\mathrm{M}$. Montello (Eds.), Stories matter: The role of narrative in medical ethics (pp. 196-218). London: Routledge.

Paley, V. (1995). Kwanzaa and me: A teacher's story. Cambridge, MA: Harvard University Press.

Paley, V. (1997). The girl with the brown crayon. Cambridge, MA: Harvard University Press.

Paley, V. (1999). The kindness of children. Cambridge, MA: Harvard University Press.
Prochnik, G. (2011). In pursuit of silence: Listening for meaning in a world of noise. New York: Anchor Books.

Redlich-Amirav, D. (2015). A narrative inquiry into mothers' experiences of hope alongside adult children struggling with mental illness. Unpublished doctoral proposal. Edmonton, $A B$ : University of Alberta.

Richardson, L. (1997). Fields of play (constructing an academic life). New Brunswick, NJ: Rutgers University Press.

Saleh, M. (2014). A multiperspectival narrative inquiry into the experiences of second-generation Canadian Muslim girls and their mothers as girl participants transition from elementary to junior high school. Unpublished doctoral proposal. Edmonton, AB: University of Alberta.

Saleh, M., Menon, J., \& Clandinin, D. J. (2014). Autobiographical narrative inquiry: Tellings and retellings. LEARNing Landscapes: Inclusive Education: Socially Just Perspectives and Practices, 7(2), 271-283. Retrieved from http://www.learninglandscapes.ca/images/ documents/II-no14/II-no14-final-Ir-links.pdf

Sarbin, T. R. (2004). The role of imagination in narrative construction. In C. Daiute \& C. Lightfoot (Eds.), Narrative analysis: Studying the development of individuals in society (pp. 5-20). Thousand Oaks, CA: Sage.

Schwab, J. (1973). The practical 3: Translation into curriculum. The School Review, 81(4), 501-522. Retrieved from http://www.jstor. org/stable/1084423

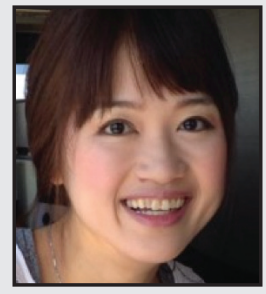

Hiroko Kubota is a registered nurse in Japan and a $\mathrm{PhD}$ candidate in the Faculty of Nursing at the University of Alberta. Her research focuses on structures of marginalization, constructions of citizenship and inequity, and philosophical thinking about human rights and human nature. Hiroko completed her Master's degree in 2012 on the "Philosophical Consideration of the Structural Marginalization of People Who Are Homeless in Japan Through the Citizenship Analysis." Her doctoral research is a "Narrative Inquiry Into the Experiences of People Who Are Homeless in Japan." 


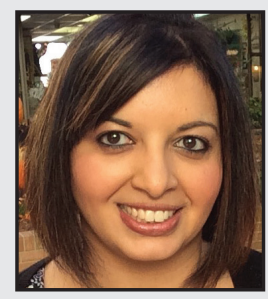

Jinny Menon is currently a PhD candidate at the University of Alberta and a member of the university's Centre for Research for Teacher Education and Development (CRTED) community. She obtained her Masters of Education in Educational Studies with a focus in school improvement and leadership at the University of Alberta in 2012. An experienced elementary school teacher and administrator, she uses a multiperspectival approach in her narrative inquiry into the diverse curriculum-making experiences of South Asian girls, mothers, and teachers in Canada.

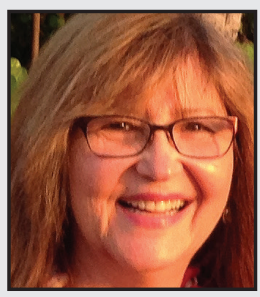

Dorit Redlich-Amirav is an occupational therapist in Israel, working in the mental health field mostly with family members. In her Master's degree, she studied hope in family members of mentally ill children, before and after a psycho-educational course, and revealed in herself an in-depth passion to know more about hope. She is a PhD candidate in the Faculty of Rehabilitation Science at the University of Alberta, Edmonton, Canada. Her research is about "Composing Lives in the Midst of the Palestinian-Israeli Conflict: A Narrative Inquiry Into Mothers' Experiences of Hope Alongside Adult Children Struggling With Mental Illnesses."

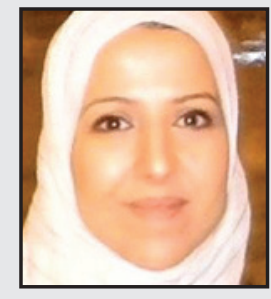

Muna Saleh is a PhD candidate in the Department of Elementary Education at the University of Alberta ( $U$ of A). She is also a member of the $U$ of A's Centre for Research for Teacher Education and Development (CRTED). For her doctoral studies, Muna draws upon her diverse experiences as an educator, parent to three children, and school board member. Following her doctoral inquiry into the experiences of Canadian Muslim girls and their mothers during a time of life transition, she is looking forward to engaging in many more narrative inquiries alongside diverse children, youth, educators, and families. 